Sharif University of Technology
Scientia Iranica
SCIENTIA
I RAN I CA
http://scientiairanica.sharif.edu

\title{
Near free-edge stresses in FRP-to-concrete bonded joint due to mechanical and thermal loads
}

\author{
H. Samadvand and M. Dehestani* \\ Faculty of Civil Engineering, Babol Noshirvani University of Technology, Babol, P.O. Box 484, Iran.
}

Received 14 March 2018; received in revised form 24 September 2018; accepted 24 December 2018

\author{
KEYWORDS \\ FRP-to-concrete \\ bonded joint; \\ Thermomechanical \\ load; \\ Free-edge interfacial \\ stress; \\ Boundary layer; \\ Debonding failure; \\ Finite element \\ method.
}

\begin{abstract}
Over the last few decades, a considerable number of theoretical and experimental investigations have been conducted on the mechanical strength of composite bonded joints. Nevertheless, many issues regarding the debonding behavior of such joints still remain uncertain. The high near free-edge stress fields in most of these joints are the cause of their debonding failure. In this study, the performance of an externally bonded Fiber-Reinforced Polymer (FRP) composite to a concrete substrate prism joint subjected to mechanical and thermomechanical loadings was evaluated using the principles of lamination theory. An inclusive Matlab code was generated to perform computations. The bond strength was estimated to take place in a region-also termed as the boundary layer-where the peak interfacial shearing and transverse peeling stresses occurred, whereas the preceding stress field was observed to be the main failure mode of the joint. The proposed features were validated by using the existing experimental data points as well as the commercial Finite Element (FE) modeling software, Abaqus. A comparison between the calculated and experimental results demonstrated favorable accord, producing quite a high average ratio. The current approach facilitates failure modeling analysis, optimal design of bonded joints, and scaling analysis among others.
\end{abstract}

(C) 2020 Sharif University of Technology. All rights reserved.

\section{Introduction}

Bonded joints are popularly preferred over mechanical bolts, rivets, and welds due to their compact design, low manufacturing cost, enhanced mechanical durability, sound/noise proof, and low weight. Accordingly, they are extensively used to transfer load on structural elements and connections of civil structures [1]. Furthermore, the problem of function degradation of such structures has turned into a serious concern over the

\footnotetext{
*. Corresponding author. Fax: +981132331707 E-mail addresses: samadvand@gmail.com (H. Samadvand); dehestani@nit.ac.ir (M. Dehestani)
}

past several years $[2,3]$. Meanwhile, thermal stresses play a very important role in studying bonded joints for a variety of reasons. On the one hand, these joints receive considerable residual thermal stresses from the fabrication process. On the other hand, the materials that behave well at elevated or low temperatures should be selected. Thus, adherends should retain their properties at such temperatures; this is particularly true about the composite materials. The adherends with a specific Coefficient of Thermal Expansion (CTE), possibly zero, are preferred [4].

From a historical point of view, Timoshenko developed the concept of free-edge stress and first considered the deflection of bimetal thermostats subjected to uniform changes in temperature [5]. Then, continuous shear springs were applied to bonded joints 
in order to determine the maximum singular stresses at the edges [6]. This joint model is characterized by simplicity, although the role of normal stresses in the failure criterion is ignored. However, the aforementioned joint model and the associated interfacial stress solution have been adopted in many popular textbooks to perform the design and strength analysis of these types of joints. Following the introduction of classic models, there have been a significant number of theoretical complements to them. For instance, an efficient adhesively bonded joint model based on the elementary Euler-Bernoulli beam theory was formulated [7] with emphasis on all mechanical properties and geometries of the adhesively bonded joints, in which the adherends were treated as Euler-Bernoulli beams and the adhesive layer was ignored due to its negligible deformation across the thickness. So far, with the fast development of microelectronics since the 1970s, thermal stress-induced debonding failure of the so-called packaging has become one of the main technical concerns and has attracted significant academic interest over the last few decades. For instance, an innovative bonded joint model was developed within the framework of 2D elasticity in [8]. This model predicted the reasonable location of the peak interfacial shear stress at a distance of about $20 \%$ from the free end of the adherend, without considering the normal stress field. An analytical solution of the stress-strain relation of a bonded joint was developed in [9], from which a parametric study of the overlap length and thickness of layers was carried out.

Since the 1990s, several improved methods for conducting stress analysis of bonded joints have been reported in the literature. For instance, engineering solutions to the singular stress field near the interface edge of bimaterials were proposed in [10]. Furthermore, an analytical elastoplastic model of bonded joints was presented, which was then verified by using Finite Element Method (FEM) [11]; Sayman also conducted an analytic study and concluded that the strength of adhesively bonded joints could be increased by introducing proper residual stresses. A model of layer-wise adhesively bonded joints was formulated, from which the divided sub-layers were treated as field variables and solved through a set of governing Ordinary Differential Equations (ODEs) by evoking the theorem of minimum strain energy [12]. An experimental investigation [13] into the suitability of Carbon Fiber-Reinforced Polymer (CFRP) for strengthening the concrete-filled steel tubular members under flexure was conducted. It was shown that the presence of CFRP on the outer limits significantly increased the performance of beams. The efficiency of nearsurface-mounted method for both flexural and shear strengthening of Reinforced Concrete (RC) beams was examined by applying an innovative manually-made
CFRP bar through experimental and numerical investigations [14]. They defined 8-noded solid elements to represent concrete beams and introduced link elements for modeling FRP by Ansys software. It was indicated that using the proposed bars significantly improved the shear capacity of deficient concrete beams. In a peer study, the flexural performance of FRP-strengthened RC beams under cyclic loads was examined to assess its flexural behavior [15]. Eight RC beams under monotonic and cyclic loadings were tested and the results were presented in the form of load-deflection curves, reporting initiation and propagation of the interfacial debonding at mid-span for specimens with end-anchor plates. In a partly similar experimental study, the debonding mechanism for FRP-strengthened $\mathrm{RC}$ beams within the framework of $\mathrm{FE}$ was studied in [16]. After investigating the effects of length and width of the strengthening sheet on the beam's behavior and its failure mechanism, it was proved that longer FRP sheets increased the load-carrying capacity. Moreover, analysis of a membrane element of an FRP-strengthened concrete beam-column joint was proposed in [17]. The effects of bonding of steel, FRP, and concrete were considered in predicting the shear strength. It was found that even a low quantity of FRP could enhance the shear capacity of a joint by increasing the confinement. In addition, shear-torsion interaction and cracking load of RC beams via FRP sheets were investigated in [18]. Lower-strengthened specimens were discovered to have undergone a greater capacity increase. Furthermore, the flexural and impact behaviors of Glass Fiber-Reinforced Polymer (GFRP) laminates exposed to elevated temperatures were investigated in [19]. It was pointed out that the flexural and impact properties of laminates were reduced by increasing temperature. They also observed that laminates with unidirectional fibers had the best performance subjected to elevated temperatures. A micro-modeled computational framework for simulating tensile response and tension-stiffening behaviors of FRP-strengthened RC elements was presented in [20]. The bond stresses at the FRP-to-concrete interface were then computed based on the local stress transfer mechanisms. An FE model to characterize the interfacial shear strength between polymer matrices and single filaments was developed in [21]. A statistical study was then followed to evaluate the influence of key geometrical test parameters on the variability of interfacial shear strength values. The RC beam specimens strengthened by strips with bonded CFRP fan-shaped end anchorages to tension region were examined in [22]. It was indicated that the number of anchorages applied to the ends of CFRP strips was more effective than the width of CFRP strips, concerning strength and stiffness of the specimens. A numerical solution to calculating the interfacial stress 
distribution in beams strengthened with the FRP plate with the tapered ends subjected to thermal loading was developed by applying the Finite Difference Method (FDM) in [23]. They investigated the effects of different profiles on stress concentration reduction. Yet, the assumptions of parabolic through-thickness shear stress were simplified, and correction factors were considered in the methodology.

Some researchers have conducted a thermal analysis on the hybrid GFRP-concrete deck [24]. They theoretically investigated the CTE of GFRP laminates on a micro scale. Based on this analysis, the thermal behavior of composite girders with a hybrid GFRPconcrete deck was studied on a macro scale, from which the results were more conservative than those of FEM outputs. Others developed a combined experimentalnumerical approach to characterizing the effect of cyclic-temperature environment on bonded joints [3] Experimental tests were performed on single-lap joints with CFRP and steel adherends in a cyclic-temperature environment. It was then confirmed that adhesively bonded joints were allowed to have more uniform stress distribution, joint complex shapes, and low structural weight. An externally bonded CFRP plate used to reinforce the concrete beam was utilized in order to predict the interfacial stresses in the adhesive layer accounting for various effects of Poisson's ratio and Young's modulus of the layer [25]. However, the adherend shear deformations were assumed to be due to the parabolic shear stress through thickness of the layers. Furthermore, a higher-order method was used in [26] to study thick composite tubes under a combination of loads. By using the mentioned analytical approach, the displacement field of elasticity for a laminated composite tube was obtained to calculate stresses. In addition, a higher-order theory was used for conducting hygrothermal analysis of laminated composite plates in [27], satisfying the inter-laminar shear stress continuity at the interfaces and the zero transverse shear stress conditions at the top and bottom of the plate. They employed a 9-noded $\mathrm{C}^{0}$ continuous isoparametric element to simulate the FE model.

In spite of the many research works done and widespread use of regression analysis and fitting, some issues still remain unresolved when applying the above adhesively bonded joint models for determining the stress field in composite bonded joints, in which stress singularities occur at the end of binding lines and laminate interfaces. As a matter of fact, transverse deformation plays a critical role in delamination failure of composite joints, in which the transverse modulus of composite laminates is very low.

\subsection{Research attributes}

The main objective of this work is to establish two in- terfacial shear and transversely normal stress functions by integrating the geometric, mechanical, and thermal parameters of the joint under consideration in order to accurately determine the stress field distributions along the interface of the CFRP cover and concrete substrate layers. The salient feature of the approach is that it satisfies all the Boundary Conditions (BCs) in the joint exactly as necessitated by the theoretical framework, a feature ignored by many related preceding works, even the renowned ones. Furthermore, the approach expresses two simple and explicit equations for defining the interfacial shear and transversely normal stress fields at any point of the bonding line. In addition, this approach can be employed to extend the scope of failure modeling analysis, optimal design of bonded joints, and scaling analysis by altering the type of loading, joint configurations, material type, etc. Moreover, the application of this approach casts light on the problem without conventional oversimplifications, leading to the closed-form determination of the cited stress fields.

\section{Stress analysis through thermo-elastic lamination theory}

In this section, the determination of the interfacial shear and normal stresses of the externally-bonded FRP-to-concrete joints subjected to mechanical and thermomechanical loads is discussed in detail. The stress analysis conducted is based on the mechanics of the composite materials approach incorporated by the efficient algorithms in Matlab software. The generated computational code embraces all the mechanical, thermal, and geometric properties of layers, in addition to the external loadings of the joint.

In order to develop the stress-strain relationship for the layers of the joint, the $2 \mathrm{D}$ constitutive equation for each layer must be established as Eq. (1):

$$
\left[\begin{array}{c}
\sigma_{x} \\
\sigma_{y} \\
\tau_{x y}
\end{array}\right]=\left[\begin{array}{lll}
\bar{Q}_{11} & \bar{Q}_{12} & \bar{Q}_{16} \\
\bar{Q}_{21} & \bar{Q}_{22} & \bar{Q}_{26} \\
\bar{Q}_{61} & \bar{Q}_{62} & \bar{Q}_{66}
\end{array}\right]\left[\begin{array}{c}
\varepsilon_{x}-\varepsilon_{x}^{T} \\
\varepsilon_{y}-\varepsilon_{y}^{T} \\
\gamma_{x y}-\gamma_{x y}^{T}
\end{array}\right],
$$

where $\bar{Q}_{i j}$ is the transformed reduced stiffness coefficient. The $[\bar{Q}]$ can be expressed by Eq. (2):

$$
[\bar{Q}]=[T]^{-1}[Q][R][T][R]^{-1}
$$

where $[T]$ is termed the transformation matrix and is defined by Eq. (3):

$$
[T]=\left[\begin{array}{ccc}
\cos ^{2} \theta & \sin ^{2} \theta & 2 \sin \theta \cos \theta \\
\sin ^{2} \theta & \cos ^{2} \theta & -2 \sin \theta \cos \theta \\
-\sin \theta \cos \theta & \sin \theta \cos \theta & \cos ^{2} \theta-\sin ^{2} \theta
\end{array}\right] .
$$

$[R]$ is the Reuter matrix. The inverse of compliance 
matrix is $[Q]$, the stiffness matrix, i.e., $[Q]=[S]^{-1}$. The compliance matrix, $[S]$, can be expressed in Eq. (4) in terms of the engineering constants of the material, which can be written as follows:

$$
\begin{aligned}
{[S] } & =\left[\begin{array}{lll}
S_{11} & S_{12} & S_{16} \\
S_{21} & S_{22} & S_{26} \\
S_{61} & S_{62} & S_{66}
\end{array}\right] \\
& =\left[\begin{array}{ccc}
1 / E_{1} & -\nu_{12} / E_{1} & 0 \\
-\nu_{12} / E_{1} & 1 / E_{2} & 0 \\
0 & 0 & 1 / G_{12}
\end{array}\right] .
\end{aligned}
$$

To determine the strains in Eq. (1), Eq. (5) is read as follows:

$$
\left\{\begin{array}{c}
\varepsilon_{x} \\
\varepsilon_{y} \\
\gamma_{x y}
\end{array}\right\}=\left\{\begin{array}{c}
\varepsilon_{x}^{0} \\
\varepsilon_{y}^{0} \\
\gamma_{x y}^{0}
\end{array}\right\}+z\left\{\begin{array}{c}
\kappa_{x} \\
\kappa_{y} \\
\kappa_{x y}
\end{array}\right\}+\left\{\begin{array}{c}
\varepsilon_{x}^{T} \\
\varepsilon_{y}^{T} \\
\gamma_{x y}^{T}
\end{array}\right\},
$$

where $\varepsilon^{0}, \kappa$, and $\varepsilon^{T}$ terms are the midplane strains, curvatures, and thermal strains, respectively; Eq. (5) is considered to be the fundamental equation of lamination theory. The total strains comprise superposition of the midplane strains, the strains associated with curvature, and the strains originating from thermal effects. It is worth noticing that this result was achieved without determining the type of material in advance or knowing whether or not the layer is composed of more than one ply. The mentioned result was derived from Kirchhoff's assumptions about the displacements, considering that the direction normal to the midplane remained straight and normal to the deformed midplane after deformation; the direction normal to the midplane did not change length; and the displacements were independent of material considerations [4].

Now, only if the midplane and thermal strains and curvatures are known, the stress state can be determined using the constitutive Eq. (1). The $z$ in Eq. (5) is the point of interest at which the stresses and strains are calculated and measured from the midplane. The midplane strains and curvatures can be measured using Eq. (6) as follows:

$$
\left\{\begin{array}{c}
\varepsilon_{x}^{0} \\
\varepsilon_{y}^{0} \\
\gamma_{x y}^{0} \\
\kappa_{x} \\
\kappa_{y} \\
\kappa_{x y}
\end{array}\right\}=\left[\begin{array}{ll}
{[A]} & {[B]} \\
{[B]} & {[D]}
\end{array}\right]\left\{\begin{array}{c}
N_{x}+N_{x}^{T} \\
N_{y}+N_{y}^{T} \\
N_{x y}+N_{x y}^{T} \\
M_{x}+M_{x}^{T} \\
M_{y}+M_{y}^{T} \\
M_{x y}+M_{x y}^{T}
\end{array}\right\}
$$

where $[A],[B]$, and $[D]$ matrices denote extensional, coupling, and bending compliance matrices, respectively, and are defined by Eq. (7):

$$
\begin{cases}A_{i j}=\sum_{k=1}^{n}\left[\bar{Q}_{i j}\right]_{k} t_{k} & i=1,2,6 \\ B_{i j}=1 / 2 \sum_{k=1}^{n}\left[\bar{Q}_{i j}\right]_{k} t_{k}^{2} & i=1,2,6 \\ D_{i j}=1 / 3 \sum_{k=1}^{n}\left[\bar{Q}_{i j}\right]_{k} t_{k}^{3} & i=1,2,6\end{cases}
$$

where $t_{k}$ is the thickness of the $k$ th layer. The resulting forces and moments are expressed in the following. $N_{x}$ and $N_{y}$ are normal forces, and $N_{x y}$ is the shear force per unit length. Likewise, $M_{x}$ and $M_{y}$ are the bending moments, and $M_{x y}$ is the twisting moment per unit length. Hence, the only remaining consideration for thermo-elastic lamination theory is the utilization of the equivalent thermal force, $N^{T}$, and the equivalent thermal moment, $M^{T}$. These quantities are titled equivalent forces and equivalent moments, respectively, since they have units of force and moment per unit length and are not physically applied forces and moments.

\section{Problem modeling}

Figure 1(a) and (b) show the configuration of the composite bonded joint comprising a straight CFRP cover layer and a concrete substrate bar, together

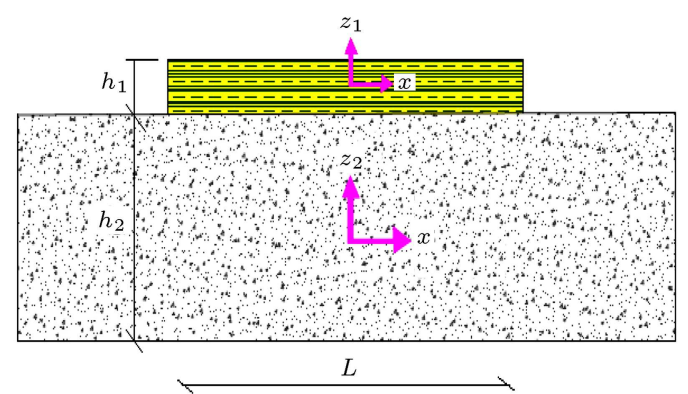

(a)

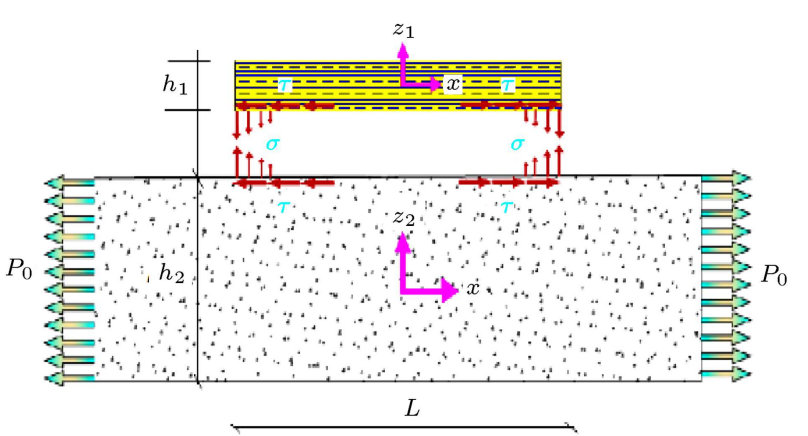

(b)

Figure 1. Configuration of the joint consisting of a straight CFRP cover and a concrete substrate with distribution of near free-edge interfacial stresses: (a) Bonded joint and (b) distribution of interfacial shear $(\tau)$ and normal $(\sigma)$ stresses. 
with the resulting interfacial shear $(\tau)$ and normal $(\sigma)$ stresses, where the bonding line is denoted by $L$. The beam is assumed to be subjected to the action of uniform axial tension, $P_{0}$, which is applied to both ends of the tension bar, namely the concrete substrate layer. Subscripts 1 and 2 are designated to the cover layer and substrate bar, respectively. The layers enjoy the mechanical properties of Young's modulus $E_{i}(i=1,2)$ and Poisson's ratio $\nu_{i}(i=1,2)$ as well as the geometric parameters of thickness $h_{i}(i=1,2)$ and CTE $\alpha_{i}$ $(i=1,2)$. The width is denoted by $b$. The $x$-coordinate in a $2 \mathrm{D}$ model is taken from the mid-span of the joint; the $z$-coordinate is selected perpendicular to the $x$ coordinate and along the layer edge.

The adherends of bonded joints are in a complicated three-dimensional stress state. This is mainly due to the varying Poisson's ratios across the adherends' interface. To facilitate the analysis process, the joint was considered to be in the plane-stress state and subjected to a uniform temperature change $\Delta T$ relative to the reference temperature. The interfacial shear and normal stresses might result from the mismatch of material properties along the bonding line; lateral deflection was probably induced since the joint was not laterally symmetric. The joint layers were treated as isotropic for the concrete substrate bar and transversely isotropic for the CFRP cover layer and linearly thermoelastic materials.

Thereafter, based on the commercial Finite Element Analysis (FEA) software package Abaqus, FEM was employed to further authenticate the proposed composite approach. Through the course of applying FEM for the joint, the 8-noded linear elements (C3D8R) and exclusively hexahedral meshes were employed, as well. A nonuniform biased distribution of elements along the bondline was used to exhibit the trend of singular stresses along the bondline, as shown in Figure 2. In addition, as illustrated in Figure 3, two of the substrate ending edges were used to constrain the movement of the selected degrees of freedom toward zero so as to simulate the BCs.

The whole solving process was executed by programing a robust Matlab code encompassing all the

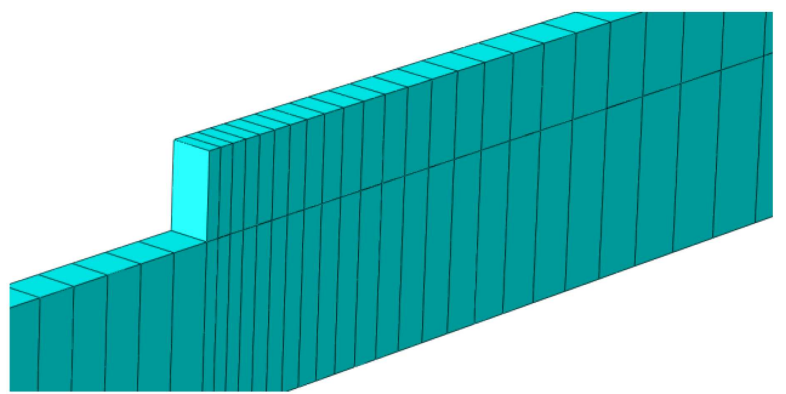

Figure 2. Representative of the biased mesh grid density of bonded joint.

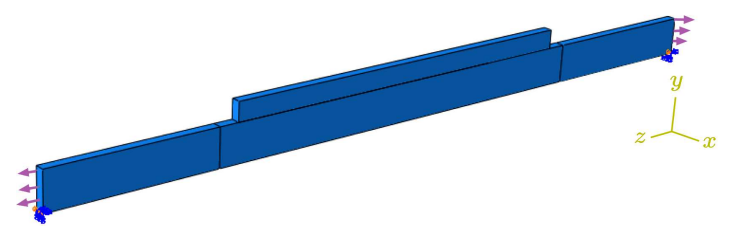

Figure 3. Loading and Boundary Conditions (BCs) applied to ending edges of the concrete substrate.

mechanical properties, geometries, and external thermal load of the joint. Consequently, the entire stress field of the bonded joint can be determined accurately, which is validated by the existing models in the literature. The detailed workflow of the stress coefficients derivation is given in Figure 4. It characterizes the incremental analysis procedure flowchart for the FRP-to-concrete composite bonded joint model under consideration.

\section{Governing equation of interfacial stress functions}

Figure 5(a) and (b) illustrate the typical representative segmental elements of the reinforcing CFRP-laminate and the concrete substrate layer together with the stress resultants, conforming to the conventional sign standards [28]. Therefore, as in the representative segmental element of the reinforcing patch (Figure 5(a)), two of static equations of equilibrium are expressed by Eqs. (8) and (9):

$$
\begin{aligned}
& \frac{d Q_{1}}{d x}=-\sigma b, \\
& \frac{d M_{1}}{d x}=Q_{1}-\frac{\tau h_{1} b}{2} .
\end{aligned}
$$

Meanwhile, the equivalent equilibrium equations for the representative segmental element of the concrete substrate layer are formulated as Eqs. (10) and (11):

$$
\begin{aligned}
& \frac{d Q_{2}}{d x}=\sigma b, \\
& \frac{d M_{2}}{d x}=Q_{2}-\frac{\tau h_{2} b}{2} .
\end{aligned}
$$

Two unknown stress functions including the interfacial shear and normal stresses, as denoted by $\tau(x)$ and $\sigma(x)$, were adopted. Since the joint was symmetric with respect to $y$-axis, the shear stress function $\tau(x)$ and the normal stress function $\sigma(x)$ would be odd and even functions, respectively.

Furthermore, the $x$-axis was aligned horizontally so that the two unknowns could be expressed as the functions of variable $x$. The shear stress at the free edges of the bonding line, $x=-L / 2$ and $x=+L / 2$, reduced the interfacial shear stress function to zero. 


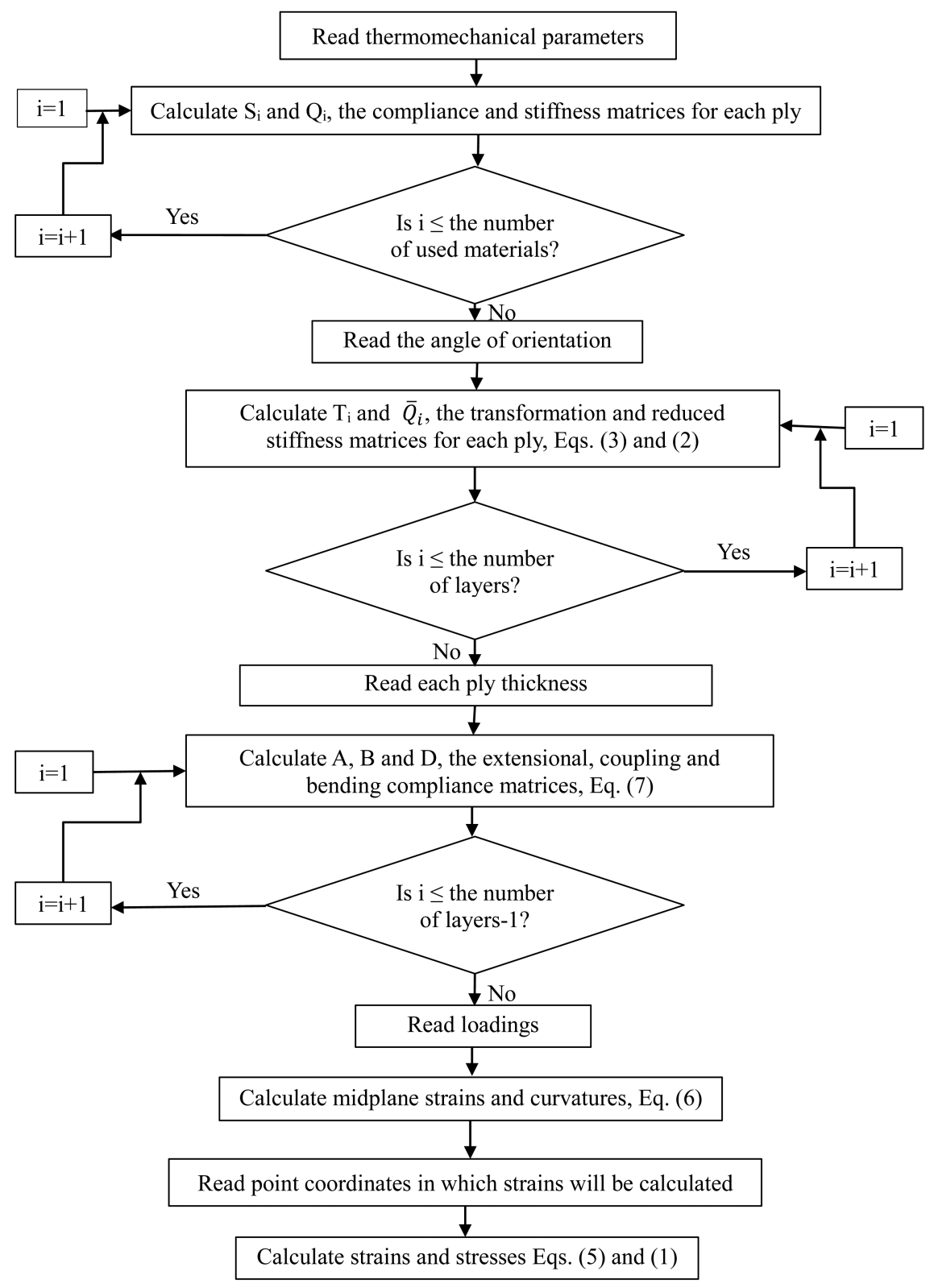

Figure 4. Incremental procedure to determine interfacial stress coefficients of the bonded joint.

Integration of Eqs. (8) and (9) with respect to $x$ from $x=-L / 2$ as well as application of the associated BCs, i.e., $Q_{1}(-L / 2)=0$ and $M_{1}(-L / 2)=0$, led to Eqs. (12) and (13), respectively:

$$
\begin{aligned}
& Q_{1}(x)=-b \int_{-L / 2}^{x} \phi(\zeta) d \zeta, \\
& M_{1}(x)=-b \int_{-L / 2}^{x} \int_{L / 2}^{\xi} \phi(\eta) d \eta d \zeta-\frac{h_{1} b}{2} \int_{-L / 2}^{x} \psi(\zeta) d \zeta .
\end{aligned}
$$

The same trend was used for the resulting stresses of the concrete substrate by integrating Eqs. (10) and (11) with respect to $x$ from $x=-L / 2$ and taking into account the relevant $\mathrm{BCs}$, i.e., $Q_{2}(-L / 2)=0$ and $M_{2}(-L / 2)=0$, for the shear and moment, respectively. The shear force, $Q_{2}(x)$, and bending moment, $M_{2}(x)$, can be simply determined using Eqs. (14) and (15) as follows:

$$
\begin{aligned}
& Q_{2}(x)=b \int_{-L / 2}^{x} \phi(\zeta) d \zeta, \\
& M_{2}(x)=b \int_{-L / 2}^{x} \int_{-L / 2}^{\xi} \phi(\eta) d \eta d \zeta-\frac{h_{2} b}{2} \int_{-L / 2}^{x} \psi(\zeta) d \zeta .
\end{aligned}
$$

In order to correlate the interfacial shear $\tau(x)$ and 


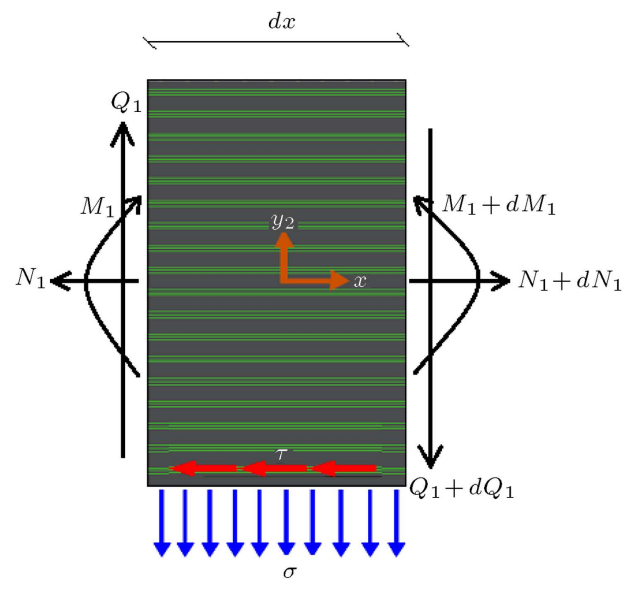

(a)

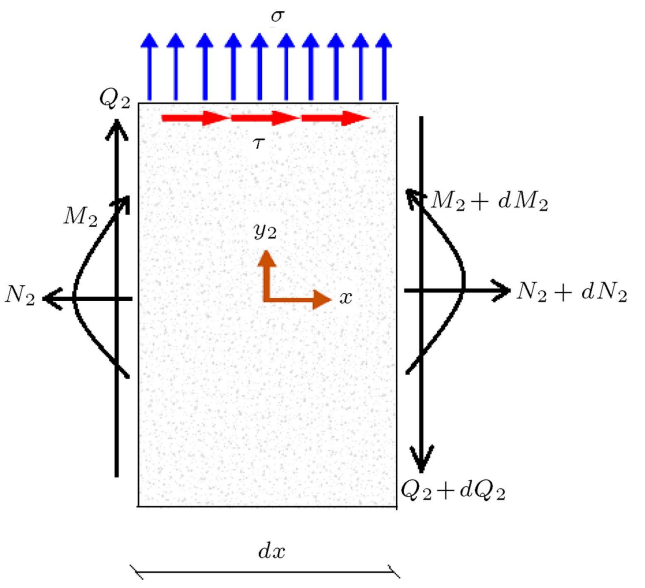

(b)

Figure 5. Free-body diagrams of representative segmental elements of the adherends: (a) Carbon Fiber Reinforced Polymer (CFRP)-composite cover and (b) concrete substrate layer.

normal $\sigma(x)$ stress functions along the interface and to simplify the calculations, the deformation compatibility, as represented by Eq. (16), was used such that the radii of curvature of CFRP-composite laminate and the concrete substrate layer were assumed to be approximately the same:

$$
\frac{1}{\rho_{1}}=\frac{1}{\rho_{2}} \equiv \frac{M_{1}}{E_{1} I_{1}}=\frac{M_{2}}{E_{2} I_{2}},
$$

where $I_{1}=1 / 12 b h_{1}^{3}$ and $I_{2}=1 / 12 b h_{2}^{3}$ are the moments of inertia of the CFRP-laminate composite and the concrete substrate layer, respectively.

Hence, substituting Eqs. (13) and (15) into Eq. (16) becomes:

$$
\begin{gathered}
-\frac{E_{2}}{E_{1}}\left(\frac{h_{2}}{h_{1}}\right)^{3}\left[\int_{-\frac{L}{2}}^{x} \int_{-\frac{L}{2}}^{\xi} \sigma(\eta) d \eta d \xi-\frac{h_{1}}{2} \int_{-\frac{L}{2}}^{x} \tau(\xi) d \xi\right] \\
=\int_{-\frac{L}{2}}^{x} \int_{-\frac{L}{2}}^{\xi} \sigma(\eta) d \eta d \xi-\frac{h_{2}}{2} \int_{-\frac{L}{2}}^{x} \tau(\xi) d \xi
\end{gathered}
$$

By differentiating both sides of Eq. (17) and defining the parameters as $e_{21}=E_{2} / E_{1}, h_{21}=h_{2} / h_{1}$, and $\eta_{0}=e_{21} h_{21}^{3}+1 /\left(e_{21} h_{21}^{3}-1\right)$, Eq. (17) can be reduced to Eq. (18) as follows:

$$
\tau(x)=-2 \frac{\eta_{0}}{h_{2}} \int_{-L / 2}^{x} \sigma(\zeta) d \zeta
$$

Then, the entire strain energy of the CFRP-to-concrete joint is determined by integrating the strain energy density (per unit length) with respect to the $x$ from $x=-L / 2$ to $x=+L / 2$, as given in Eq. (19):

$$
\begin{aligned}
U= & b \int_{-\frac{L}{2}}^{\frac{L}{2}} \int_{-h_{1} / 2}^{h_{1} / 2}\left\{\frac{1}{2}\left[\sigma_{x x}^{(1)} \varepsilon_{x x}^{(1)}+\sigma_{y y}^{(1)} \varepsilon_{y y}^{(1)}\right]\right. \\
& \left.+\frac{1+\nu_{1}}{E_{1}}\left(\tau_{y_{1} x}^{(1)}\right)^{2}\right\} d x d y_{1} \\
& +b \int_{-\frac{L}{2}-h_{2} / 2}^{\frac{L}{2}}\left\{\frac{1}{2}\left[\sigma_{x x}^{(2)} \varepsilon_{x x}^{(2)}+\sigma_{y y}^{(2)} \varepsilon_{y y}^{(2)}\right]\right. \\
& \left.+\frac{1+\nu_{2}}{E_{2}}\left(\tau_{y_{2} x}^{(2)}\right)^{2}\right\} d x d y_{2} .
\end{aligned}
$$

The aforementioned complementary strain energy is a functional with respect to the unknown interfacial stress function $\tau(x)$.

Based on the theorem of minimum complementary strain energy, the complementary strain energy of the joint with respect to the interfacial stress function, $\tau(x)$, reaches a stationary point in static equilibrium such that $\partial U=0$, where $\delta$ is the mathematical variational operator with respect to the unknown interfacial shear stress, $\tau(x)$. By setting it equal to zero, the 4 thorder ODE was yielded with respect to the interfacial shear stress $\tau(x)$ as Eq. (20):

$$
\Psi^{I V}(\zeta)-2 p \Psi^{I I}(\zeta)+q^{2} \Psi(\zeta)+t=0 .
$$

In Eq. (9):

$$
\Psi(\zeta)=\Psi\left(\frac{x}{h_{1}}\right)=-\left(\frac{1}{P_{0 h_{1}}}\right) \int_{-L / 2}^{x} \tau(x) d x
$$

is a dimensionless stress function; the coefficients $p=$ $B /(-2 A), q=\sqrt{C / A}$, and $t=D / A$ are related to the properties of the joint. Moreover, each of the 
coefficients $A, B, C$, and $D$ is in turn solved by using an efficient code generated by the authors in Matlab, as elaborated in Figure 4.

Mathematically, in the case of $q>p$, the solution to Eq. (9) gives the following:

$$
\begin{aligned}
\Psi(\zeta)= & C_{1} \cosh (\mu \zeta) \cos (\omega \zeta)+C_{2} \sinh (\mu \zeta) \sin (\omega \zeta) \\
& +t / q^{2},
\end{aligned}
$$

where $\omega=\sqrt{(q-p) / 2}, \mu=\sqrt{(p+q) / 2}$, and $C_{1}$ and $C_{2}$ are constants. By applying the shear-free and axial traction-free conditions at $x= \pm L / 2, C_{1}$ and $C_{2}$ can be determined and $\tau(x)$ can be expressed as Eq. (23):

$$
\begin{aligned}
\tau(x)= & -P_{0} h_{1} \frac{d \Psi(\zeta)}{d x} \\
= & -P_{0}\left[\left(C_{1} \mu+C_{2} \omega\right) \sinh \left(\mu x / h_{1}\right) \cos \left(\omega x / h_{1}\right)\right. \\
& \left.+\left(-C_{1} \omega+C_{2} \mu\right) \cosh \left(\mu x / h_{1}\right) \sin \left(\omega x / h_{1}\right)\right] .
\end{aligned}
$$

In addition, if $p>q$, the solution to Eq. (9) yields the following:

$$
\Psi(\zeta)=C_{1} \cosh (\mu \zeta)+C_{2} \cosh (\omega \zeta)+t / q^{2}
$$

where $\omega=\sqrt{p-\sqrt{p^{2}-q^{2}}}, \mu=\sqrt{p+\sqrt{p^{2}-q^{2}}}$, and $C_{1}$ and $C_{2}$ are two constants. By plugging the shearfree and axial traction-free conditions at $x= \pm L / 2, C_{1}$ and $C_{2}$ can be determined and $\tau(x)$ can be expressed as in Eq. (25):

$$
\begin{aligned}
\tau(x) & =-P_{0} h_{1} \frac{d \Psi(\zeta)}{d x} \\
& =-P_{0}\left[C_{1} \mu \sinh \left(\mu x / h_{1}\right)+C_{2} \omega \sinh \left(\omega x / h_{1}\right)\right] .
\end{aligned}
$$

Accordingly, the interfacial normal stress $\sigma(x)$ related to $\tau(x)$ through Eq. (18) can be defined as in Eq. (26):

$$
\sigma(x)=-\frac{h_{2}}{2 \eta_{0}} \tau^{\prime}(x)
$$

\section{Validating process}

In order to validate the present model, herein, the thermomechanical stress analysis of a bimaterial thermostat subjected to a uniform temperature change [2931] was considered. Consistent with the coordinate system depicted in Figure 1, the parameters:

$$
\begin{aligned}
& h_{1}=2.5 \mathrm{~mm}, \quad E_{1}=70 \mathrm{GPa}, \quad \nu_{1}=0.345, \\
& \alpha_{1}=23.6 e-61 / C, \quad h_{2}=2.5 \mathrm{~mm}, \quad E_{2}=325 \mathrm{GPa}, \\
& \nu_{2}=0.293, \quad \alpha_{2}=4.9 e-61 / C, \quad L=50.8 \mathrm{~mm}, \\
& \text { and } \quad \Delta T=240^{\circ} \mathrm{C}
\end{aligned}
$$

where $\alpha_{i}$ is the CTE with respect to the principal material directions.

By substituting the aforementioned values into Eqs. (25) and (26) and determining interfacial shear and normal stresses of the joint subjected to mechanical and thermomechanical loads for a joint model with a given set of parameters, the analysis includes each of the resulting interfacial shear and normal stress fields that can be expressed explicitly through the simple and straightforward Eqs. (27) and (28), respectively:

$$
\begin{aligned}
\tau_{x z}= & 4.2328 \times 10^{-015} \sinh (1.5631 x) \\
& -2.2095 \times 10^{-009} \sinh (1.0448 x),
\end{aligned}
$$

where $\tau_{x z}$ is the interfacial thermal shear stress and:

$$
\begin{aligned}
\sigma_{z z}= & 1.8629 \times 10^{-009} \cosh (1.0448 x) \\
& -5.3392 \times 10^{-015} \cosh (1.5631 x),
\end{aligned}
$$

where $\sigma_{z z}$ is the interfacial thermal normal stress along the bonding line.

Figure 6(a) and (b) show the distribution of

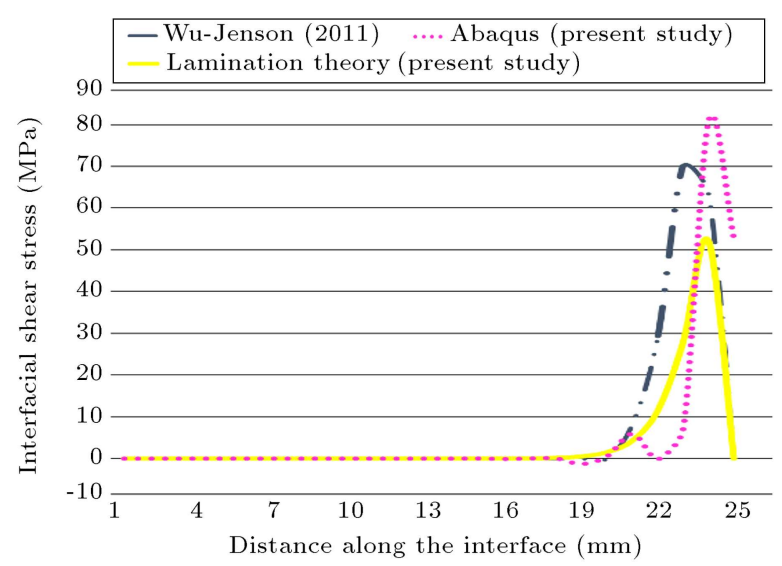

(a)

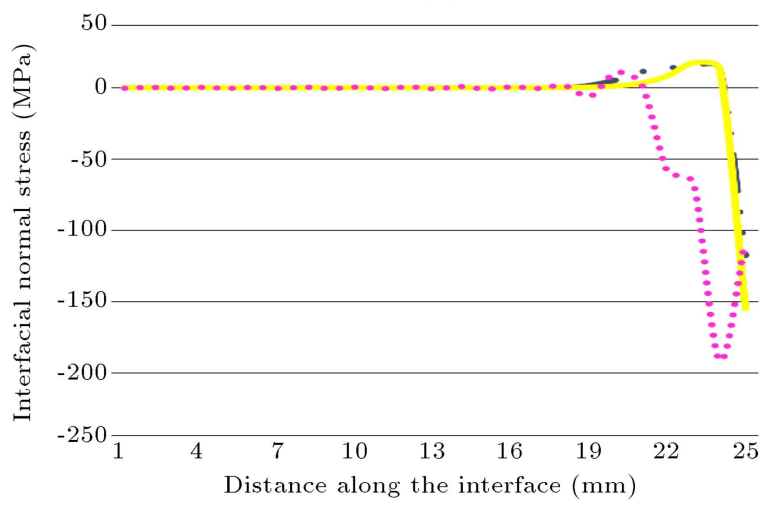

(b)

Figure 6. Comparison of the stresses proposed by the present model with those by $\mathrm{Wu}$ and Jenson and FEM due to a uniform change of temperature $\Delta T$ : (a) Interfacial thermal shear stress $(\tau)$ and (b) interfacial thermal normal stress $(\sigma)$. 
the interfacial thermal shear and normal stress fields of the tested joint subjected to uniform changes in temperature $\Delta T$, which were predicted by the present lamination theory approach and compared with those obtained by FEM (Abaqus) and those in [32] along the interface. It can be observed that the shearing and peeling stresses are highly localized at the near freeend of the bondline. Obviously, the interfacial shear stresses predicted by the present lamination theory approach exactly satisfy the shear-free BCs in the joint, as required by the theoretical formulation.

Even though the normal and shear stresses exhibited very similar variation trends for the proposed approach, FEM, and those of [32], shear stress results obtained by FEM did not satisfy the stress-free BCs at the very ending edges of the cover layer because of the singular state of such stresses. However, the peak values took place at the same point as those of the lamination theory approach. The interfacial shear stress values were 25 and $35 \%$ lower at the adherend end than those predicted by $\mathrm{Wu}$ and Jenson [32] and FEM, respectively. This can be due to the lower-order nature of the approach in the current work. Moreover, the peak values of normal stresses predicted by the formulations in the present study were 30\% higher and $20 \%$ lower than those of [32] and FEM with the same geometries, material properties, and temperature change. After employing the temperature change to the joint, the cover layer showed greater thermal expansion and tended to endure larger deformations due to the large CTE than the substrate layer at a gross ratio of 5 to 1 .

\section{Scaling analysis}

In terms of scaling analysis, the present solution to the interfacial stresses in bonded joints has more advantages than the conventional approaches such as simplicity and explicit expressions of the stress components. A compact and efficient computational Matlab code was designed and implemented to examine the dependency of the interfacial shear and normal stresses on the temperature parameter, as well as other mechanical variables. Table 1 depicts the mechanical and geometric properties of concrete substrate in the scaling analysis. Likewise, Table 2 displays the mechanical and geometric properties of the CFRP composite cover layer in this section.

To carry out the scaling analysis of thermomechanical stresses in the joint, four positive and four negative temperatures, ranging from $\Delta T=25^{\circ} \mathrm{C}$ to $\Delta T=100^{\circ} \mathrm{C}$ and $\Delta T=-25^{\circ} \mathrm{C}$ to $\Delta T=-100^{\circ} \mathrm{C}$ at a span of 25 were adopted. Figure $7(\mathrm{a})$ and (b) and Figure 8(a) and (b) illustrate the variations in the interfacial shear and normal stresses with distance $x$ from the left end of the CFRP cover layer for positive and negative thermal loads, respectively.

It is perceived that shear and normal stresses are symmetric with respect to the mid-span of the joint. According to Figure 7(a) and (b), as the positive values of temperature increased, the interfacial shear stress field increased in the near free-edge zone. Specifically, the peak values of interfacial shear stress appeared at a distance close to free ends, also termed the boundary layer region. In this research, the distance was measured to be the $L / 8$ from the free edges. The shear stress was equal to zero at free edges; on the contrary, the peak values of the positive normal stress occurred exactly at free ends. As shown in Figure 8(a) and (b), the increasing trend of stresses is the same, i.e., absolute increase in temperature causes an increase in shear and normal stresses. It was then observed that the normal stresses took negative values for negative thermal loads. Due to the main contribution of shear stresses, the peak values of interfacial shear stresses were much larger than those of the normal stresses in all the cases under examination, demonstrating the dominant mode of debonding failure in the joint.

Table 1. Mechanical and geometric properties of concrete substrate prism.

\begin{tabular}{|c|c|c|c|c|c|c|c|c|}
\hline $\begin{array}{c}\text { Axial } \\
\text { modulus } \\
E_{2} \\
(\mathrm{GPa}) \\
\end{array}$ & $\begin{array}{c}\text { Shear } \\
\text { modulus } \\
G_{12} \\
(G P a) \\
\end{array}$ & $\begin{array}{c}\text { Poisson's } \\
\text { ratio } \\
\nu_{2}\end{array}$ & $\begin{array}{c}f_{c}^{\prime} \text { concrete } \\
\text { cylinder } \\
\text { strength } \\
(\mathrm{MPa})\end{array}$ & $\begin{array}{c}\text { Axial CTE } \\
\alpha_{1} \\
\left(\mu /{ }^{\circ} \mathrm{C}\right)\end{array}$ & $\begin{array}{l}\text { Thickness } \\
h_{2}(\mathrm{~mm})\end{array}$ & $\begin{array}{c}\text { Joint } \\
\text { width } \\
b(\mathrm{~mm})\end{array}$ & $\begin{array}{c}\text { Bondline } \\
\qquad \\
(\mathrm{mm})\end{array}$ & $\begin{array}{c}\text { Traction } \\
\text { load } \\
P_{0} \\
(\mathrm{MPa}) \\
\end{array}$ \\
\hline 33.8 & 14.08 & 0.2 & 50 & 10 & 50 & 50 & 100 & +1 \\
\hline
\end{tabular}

Table 2. Mechanical and geometric properties of the Carbon Fiber Reinforced Polymer (CFRP)-composite cover layer.

\begin{tabular}{|c|c|c|c|c|c|c|c|c|}
\hline CFRP & $\begin{array}{c}\text { Axial } \\
\text { modulus } \\
E_{1} \\
(\mathrm{GPa})\end{array}$ & $\begin{array}{c}\text { Shear } \\
\text { modulus } \\
G_{12} \\
(\mathrm{GPa})\end{array}$ & $\begin{array}{c}\text { Poisson's } \\
\text { ratio } \\
\nu_{1}\end{array}$ & $\begin{array}{c}\text { Axial } \\
\mathrm{CTE} \\
\alpha_{1}\left(\mu /{ }^{\circ} \mathrm{C}\right)\end{array}$ & $\begin{array}{c}\text { Thickness } \\
h_{1} \\
(\mathrm{~mm})\end{array}$ & $\begin{array}{c}\text { Joint } \\
\text { width } \\
b \\
(\mathrm{~mm}) \\
\end{array}$ & $\begin{array}{c}\text { Bondline } \\
\qquad \begin{array}{c}L \\
(\mathrm{~mm})\end{array}\end{array}$ & $\begin{array}{c}\text { Traction } \\
\text { load } \\
P_{0} \\
(\mathrm{MPa}) \\
\end{array}$ \\
\hline T300/5208 & 132 & 5.65 & 0.24 & -0.77 & 5 & 50 & 100 & +1 \\
\hline
\end{tabular}


Table 3. Mechanical and geometric properties of the joint layers.

\begin{tabular}{|c|c|c|c|c|c|c|c|c|}
\hline $\begin{array}{c}\text { CFRP } \\
\text { axial } \\
\text { modulus } \\
E_{1} \\
(\mathrm{GPa}) \\
\end{array}$ & $\begin{array}{c}\text { Concrete } \\
\text { axial } \\
\text { modulus } \\
E_{2} \\
(\mathrm{GPa}) \\
\end{array}$ & $\begin{array}{c}\text { CFRP } \\
\text { thickness } \\
h_{1} \\
(\mathrm{~mm})\end{array}$ & $\begin{array}{c}\text { Concrete } \\
\text { thickness } \\
h_{2} \\
(\mathrm{~mm})\end{array}$ & $\begin{array}{c}\text { CFRP } \\
\text { Poisson's } \\
\text { ratio } \\
\nu_{1}\end{array}$ & $\begin{array}{c}\text { Concrete } \\
\text { Poisson's } \\
\text { ratio } \\
\nu_{2}\end{array}$ & $\begin{array}{c}\text { Joint } \\
\text { width } \\
b \\
(\mathrm{~mm})\end{array}$ & $\begin{array}{c}\text { Bonding } \\
\text { length } \\
L \\
(\mathrm{~mm})\end{array}$ & $\begin{array}{c}\text { Thermal } \\
\text { load } \\
\Delta T \\
\left({ }^{\circ} \mathrm{C}\right)\end{array}$ \\
\hline 132 & 33.8 & 5 & 50 & 0.24 & 0.2 & 50 & 100 & 100 \\
\hline
\end{tabular}

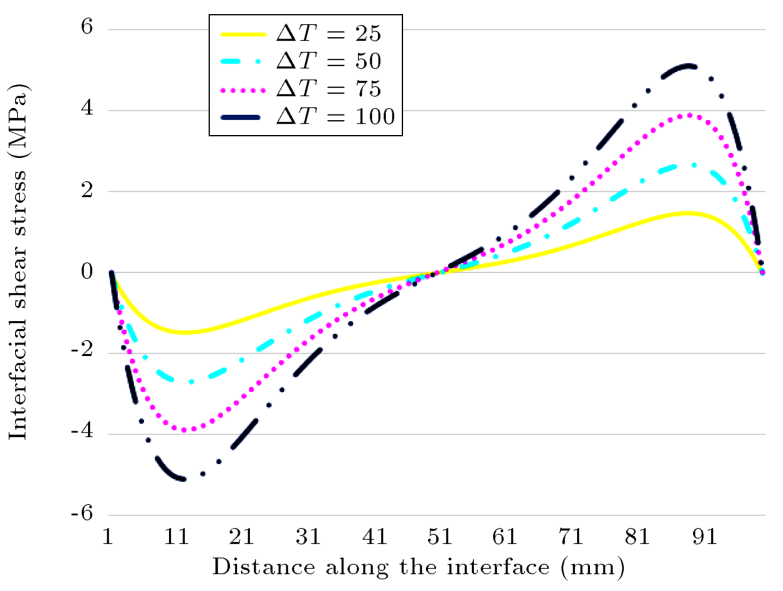

(a)

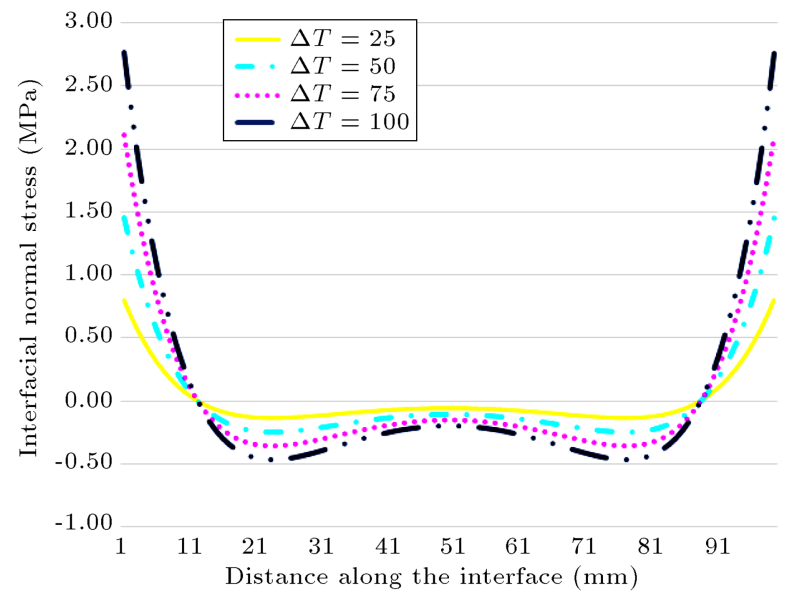

(b)

Figure 7. Variations in the interfacial shear and normal stresses with respect to positive thermal loads: (a) Interfacial shear stress $(\tau)$ and (b) interfacial normal stress $(\sigma)$.

In order to evaluate the mechanical loading effect, four positive values of $P_{0}=1,10,20$, and $30 \mathrm{MPa}$ were adopted in the study. Table 3 illustrates the joint material properties through the analysis. The distribution of the shear and normal stress fields along the interface with respect to different values of $P_{0}$ is given in Figure 9(a) and (b). It was found that the stress fields were symmetric with respect to the midspan of the joint. The stress distribution was identical to that of the thermal loading effect, though much

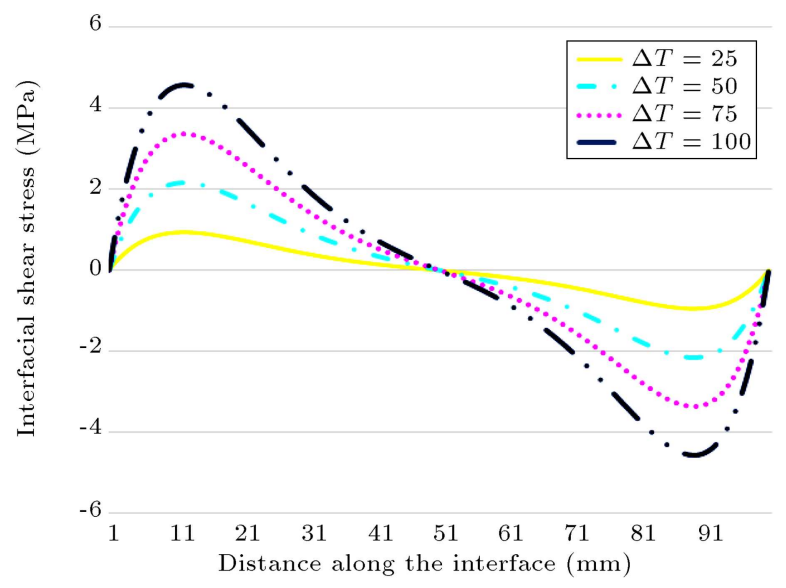

(a)

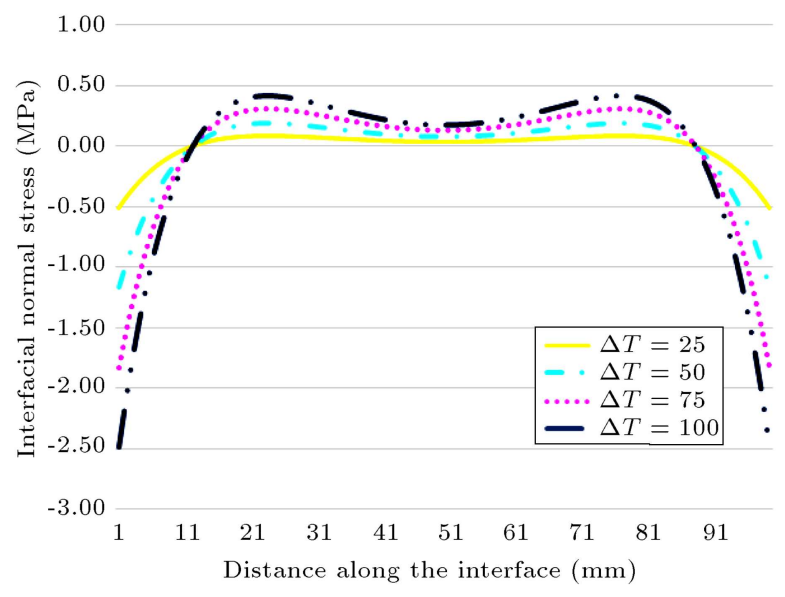

(b)

Figure 8. Variations in the interfacial shear and normal stresses with respect to negative thermal loads: (a) Interfacial shear stress $(\tau)$ and (b) interfacial normal stress $(\sigma)$.

more intense. In both Figure 9(a) and (b), the stresses increase as $P_{0}$ escalates. Additionally, four negative values of $P_{0}=-1,-10,-20$, and $-30 \mathrm{MPa}$ were assumed. Material properties are shown in Table 3, and Figure 10(a) and (b) plot variations of the interfacial shear and normal stresses along the bondline with respect to negative traction loads, respectively. As the absolute value of $P_{0}$ increased from $P_{0}=-1$ to $-30 \mathrm{MPa}$, the interfacial stresses tended to decrease down to a certain load, i.e., $P_{0}=-19 \mathrm{MPa}$, whereas 


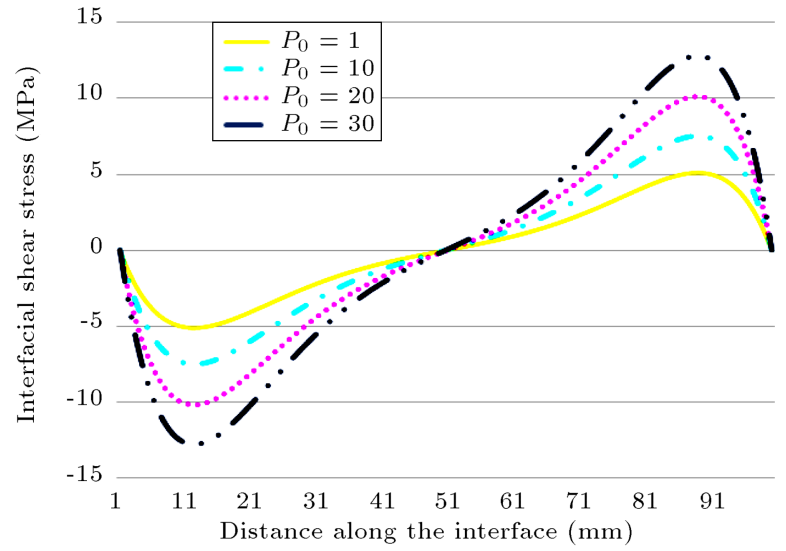

(a)

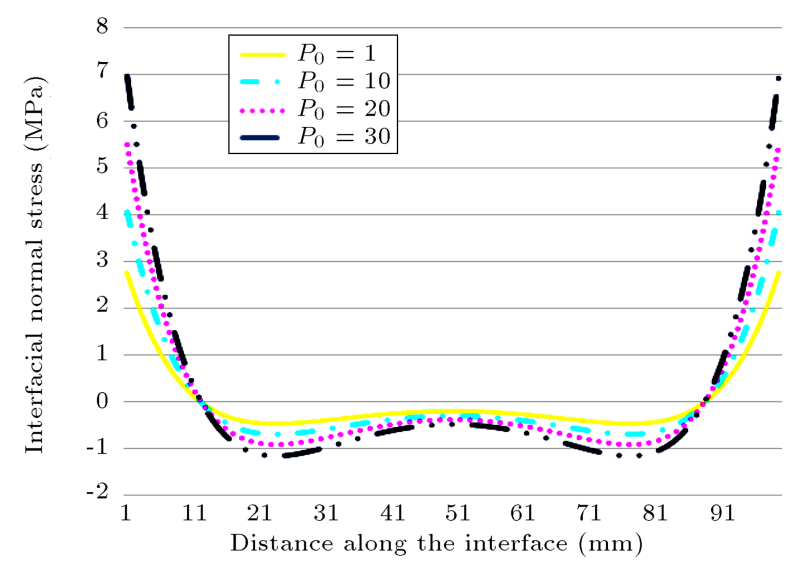

(b)

Figure 9. Variations in the interfacial shear and normal stresses with respect to positive mechanical loads: (a) Interfacial shear stress $(\tau)$ and (b) interfacial normal stress $(\sigma)$.

the curvature at this load level changed so that the peak interfacial normal stresses would appear to be negative after this loading point, having an increasing trend.

Finally, Figure 11(a) and (b) depict the distribution of interfacial shear and normal stress fields at varying temperatures with respect to different values of $P_{0}$, respectively. As the thermal load, $\Delta T$, increased from $\Delta T=-100^{\circ} \mathrm{C}$ to $\Delta T=100^{\circ} \mathrm{C}$, the shear stress decreased. Thus, for a particular thermal load, shear stress decreased, while the mechanical traction load increased. This tendency goes against the normal stresses in a sense that the increase of traction load for a specific thermal load leads to an increase in the normal stress field. According to all figures, the stress values are zero at the points without any thermal or mechanical loads.

As acknowledged using the validating process (Section 4), the obtained results of the present study showed the same quantitative features as before and were in sensibly acceptable agreement with the previous investigations. Yet, the formalism can be readily extended to the assortment of bonded structures by

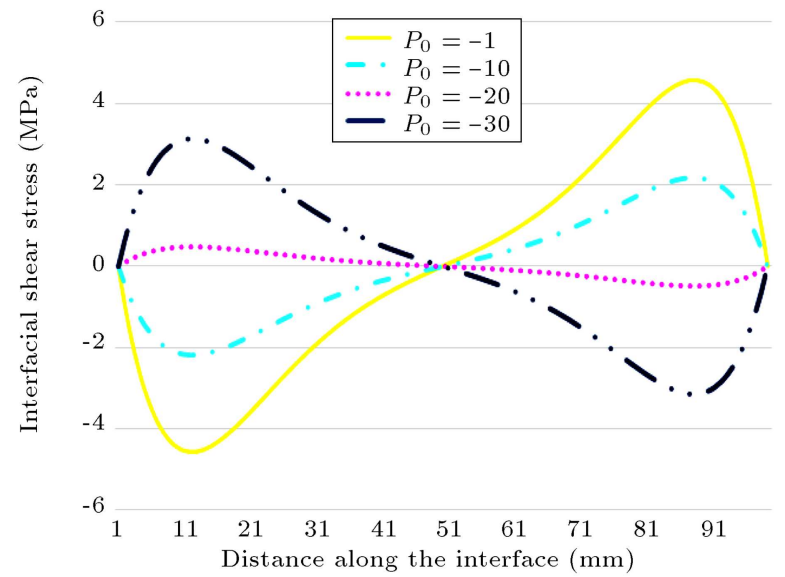

(a)

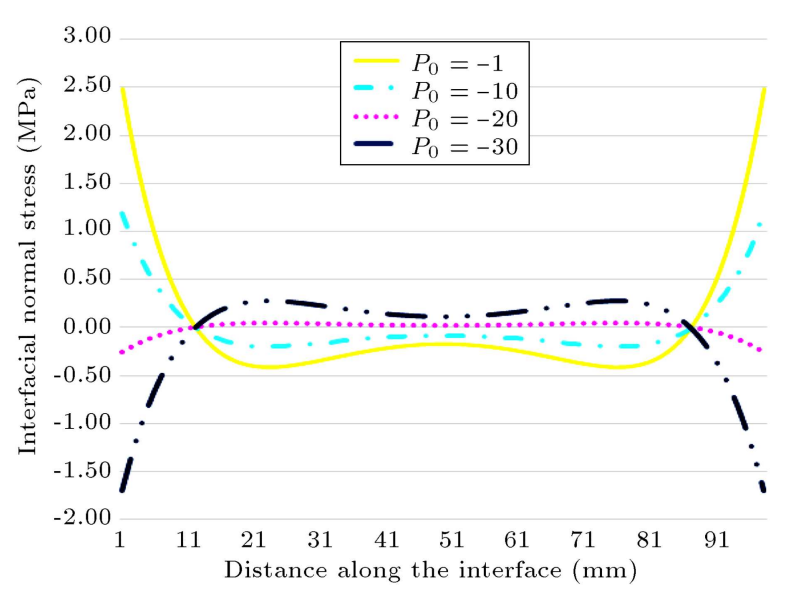

(b)

Figure 10. Variations in the interfacial shear and normal stresses with respect to negative mechanical loads: (a) Interfacial shear stress $(\tau)$ and (b) interfacial normal stress $(\sigma)$.

applying the robust computational code based on the presented theoretical approach and introducing an additional ply as the adhesive layer and plugging the mechanical and geometric properties into the algorithm to consider the effects of the adhesive layer on the stress distribution. As a result, it has the capability to provide a framework for future studies.

\section{Concluding remarks}

The performance of an externally bonded FRP-toconcrete joint subjected to mechanical and thermal loadings was evaluated. A theoretically self-consistent lower-order lamination-theory approach was proposed to establish two interfacial shear and transversely normal stress functions in terms of two simple and explicit equations by integrating the geometric, mechanical, and thermal parameters of the joint. An enhanced understanding of the scaling behavior of stress variations was obtained by devising a compact and efficient computational Matlab code to examine 


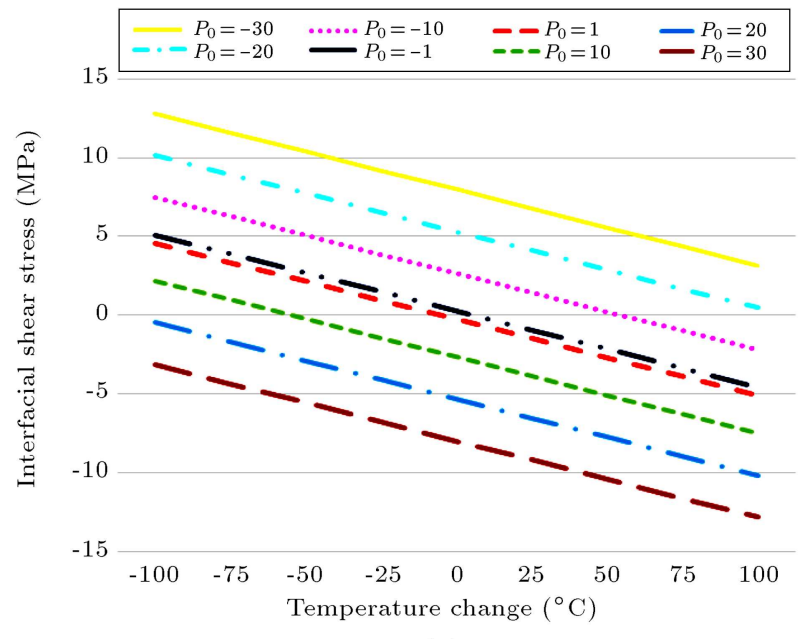

(a)

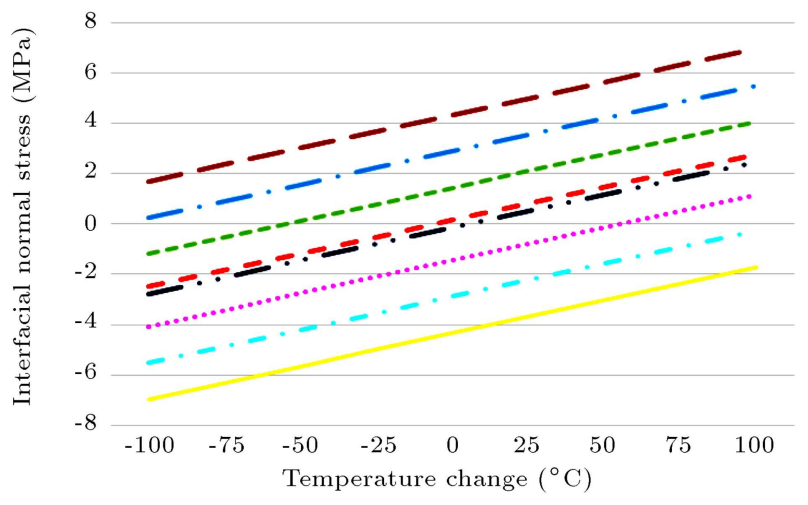

(b)

Figure 11. Stress field distribution along varying temperatures with respect to different values of $P_{0}:(a)$ Interfacial shear stress $(\tau)$ and (b) interfacial normal stress $(\sigma)$.

the dependency of the interfacial shear and normal stresses upon temperature, as well as other mechanical variables. The following conclusions were thus drawn:

1. Normal and shear stresses were characterized by the very similar varying trends for the proposed approach as to Finite Element Method (FEM), in that the peak values took place at the same points, though shear stresses obtained via FEM did not satisfy the stress-free Boundary Conditions (BCs) at the very ending edges of the bondline due to singular nature of such stresses;

2. Compared to FEM, the proposed approach proved to be more competent for stress analysis of bonded joints since it only calls for the input of basic dimensions and material properties;

3. Increase in temperature escalated both shear and normal stresses;

4. The stress distribution subjected to mechanical loading was identical to that of the thermal loading effect, yet much more intense;
5. Shear stress was equal to zero at free edges; on the contrary, the absolute peak value of normal stress occurred precisely at free ends;

6. Peak values of interfacial shear stress appeared at a distance close to free ends, termed as the boundary layer region. In this research, the length of this region was measured to be $L / 8$ from the free edges;

7. Peak values of interfacial shear stresses were much larger than normal stresses in all the cases under examination, demonstrating the dominant mode of debonding failure in the joint.

No funding source was provided in the conduction or preparation of the current research.

\section{References}

1. Goncalves, J.P.M., de Moura, M.F.S.F., and de Castro, P.M.S.T. "A three-dimensional finite element model for stress analysis of adhesive joints", Int. J. Adhesion and Adhesives, 22, pp. 357-365 (2002).

2. Zhang, Y., Vassilopoulos, A., and Keller, T. "Stiffness degradation and fatigue life prediction of adhesivelybonded joints for fiber-reinforced polymer composites", Int. J. Fatigue, 30, pp. 1813-1820 (2008).

3. Hu, P., Shi, Z.W., Wang, X., et al. "Strength degradation of adhesively bonded single-lap joints in a cyclic-temperature environment using a cohesive zone model", J. Adhesion, 91(8), pp. 587-603 (2015).

4. Herakovich, C.T., Mechanics of Fibrous Composites, University of Virginia, John Wiley and Sons, Inc. (1998).

5. Timoshenko, S. "Analysis of bi-metal thermostats", $J$. Optical Society of America, 11(3), pp. 233-255 (1925).

6. Volkersen, O. "Die nietkraftverteilung in zugbeanspruchten nietverbindungen mit konstanten laschenquerschnitten", Luftfahrtforschung, 15, pp. 41-47 (1938).

7. Delale, F., Erdogan, F., and Aydinoglu, M.N. "Stresses in adhesively bonded joints: a closed-form solution", $J$. Composite Materials, 15, pp. 249-271 (1981).

8. Chen, D. and Cheng, S. "An analysis of adhesivebonded single-lap joints", J. Applied MechanicsTransactions of ASME, 50, pp. 109-115 (1983).

9. Keller, T. and Valle'e, T. "Adhesively bonded lap joints from Pultruded GFRP profiles. Part I: Stress strain analysis and failure modes", J. Composites Part B: Eng., 36, pp. 331-340 (2004).

10. Wu, Z. and Liu, Y. "Singular stress field near interface edge in orthotropic/isotropic bi-materials", Int. $J$. Solids and Structures, 47, pp. 2328-2335 (2010).

11. Sayman, O. "Elastoplastic stress analysis in an adhesively bonded single-lap joint", J. Composites Part B, 43, pp. 204-209 (2012). 
12. Yousefsani, S.A. and Tahani, M. "Analytic solution for adhesively bonded composite single-lap joints under mechanical loadings using full layerwise theory", Int. J. Adhesion and Adhesives, 43, pp. 32-41 (2013).

13. Sundarraja, M.C. and Ganesh Prabhu, G. "Flexural behavior of CFST members strengthened using CFRP composites", Int. J. Steel and Composite Structures, 15(6), pp. 623-643 (2013).

14. Sharbatdar, M.K. and Jaberi, M. "Flexural and shear strengthening of RC beams with NSM technique and manually made CFRP bars", Scientia Iranica $A$, 25(4), pp. 2012-2025 (2018).

15. Saeidi Moein, R., Tasnimi, A.A., and Soltani Mohammadi, M. "Flexural performance of RC beams strengthened by bonded CFRP laminates under monotonic and cyclic loads", Scientia Iranica A, 23(1), pp. 66-78 (2016).

16. Mostofinejad, D. and Hosseini, S.J. "Simulating FRP debonding from concrete surface in FRP strengthened RC beams: A case study", Scientia Iranica A, 24(2), pp. 452-466 (2017).

17. Hejabi, H. and Kabir, M.Z. "Analytical model for predicting the shear strength of FRP-retrofitted exterior reinforced concrete beam-column joints", Scientia Iranica A, 22(4), pp. 1363-1372 (2015).

18. Talaeitaba, S.B. and Mostofinejad, D. "Shear-torsion interaction of RC beams strengthened with FRP sheets", Scientia Iranica A, 22(3), pp. 699-708 (2015).

19. Bazli, M., Ashrafi, H., Jafari, A., et al. "Effect of thickness and reinforcement configuration on flexural and impact behavior of GFRP laminates after exposure to elevated temperatures", J. Composites Part B, 157, pp. 76-99 (2019).

20. Ghiassi, B., Soltani, M., and Rahnamaye Sepehr, S. "Micromechanical modeling of tension stiffening in FRP-strengthened concrete elements", J. Composite Materials, 52(19), pp. 2577-2596 (2018).

21. Zhao, Q., Qian, C.C., and Harper, L.T. "Finite element study of the microdroplet test for interfacial shear strength: Effects of geometric parameters for a carbon fibre/epoxy system", J. Composite Materials, 52(16), pp. 2163-2177 (2017).

22. Kara, M.E. and Yacsa, M. "An Investigation of fan type anchorages applied to end of CFRP strips", Int. J. Steel and Composite Structures, 15(6), pp. 605-621 (2013).

23. El Mahi, B., Benrahou, K.H., Amziane, S., et al. "Effect of tapered-end shape of FRP sheets on stress concentration in strengthened beams under thermal load", Int. J. Steel and Composite Structures, 17(5), pp. 601-621 (2014).

24. Xin, H., Liu, Y., and Du, A. "Thermal analysis on composite girder with hybrid GFRP-concrete deck", Int. J. Steel and Composite Structures, 19(5), pp. 1221-1236 (2015).

25. Hadji, L., Hassaine, D.T., Ait Amar Meziane, M., et al. "Analyze of the interfacial stress in reinforced concrete beams strengthened with externally bonded CFRP plate", Int. J. Steel and Composite Structures, 20(2), pp. 413-429 (2016).

26. Yazdani, S.H. and Hojjati, M. "A high-order analytical method for thick composite tubes", Int. J. Steel and Composite Structures, 21(4), pp. 755-773 (2016).

27. Singh, S.K. and Chakrabarti, A. "Hygrothermal analysis of laminated composites using C0 FE model based on higher order zigzag theory", Int. J. Steel and Composite Structures, 23(1), pp. 41-51 (2017).

28. Beer, F., Johnston, E.R., Dewolf, J.T., and Mazurek, D.F., Mechanics of Materials, 5th Ed., McGraw Hill Press, New York (2009).

29. Suhir, E. "Thermally induced interfacial stresses in elongated bimaterial plates", J. Applied Mechanics Review, 42, pp. 253-262 (1989).

30. Eischen, J.W., Chuang, C., and Kim, J.H. "Realistic modeling of edge effect stresses in bimetallic elements", J. Electronic Packaging, 112, pp. 16-23 (1990).

31. Ru, C.Q. "Interfacial thermal stresses in bimaterial elastic beams: modified beam models revisited", $J$. Electronic Packaging-Transactions of ASME, 124, pp. 141-146 (2002).

32. Wu, X.F. and Jenson, R.A. "Stress-function variational method for stress analysis of bonded joints under mechanical and thermal loads", Int. J. Engineering Science, 49, pp. 279-294 (2011).

\section{Biographies}

Hojjat Samadvand received his MSc in Structural Engineering at Babol Noshirvani University of Technology and is currently a PhD Candidate in Structural/Earthquake Engineering at Urmia University. His major areas of interest are the mechanics of reinforced concrete structures and nano-composite materials, as well as numerical modeling. He has already presented several articles in the leading international and national conferences on Civil Engineering including ICCE and NCCE.

Mehdi Dehestani is currently an Associate Professor of Civil Engineering at Babol Noshirvani University of Technology, Babol, Iran. He is also a faculty member of the Structural and Earthquake Engineering at Babol Noshirvani University of Technology. He received his $\mathrm{PhD}$ degree in Structural and Earthquake Engineering from Sharif University of Technology, Tehran, Iran. His research expertise lies in the area of reinforced concrete structures, specifically the application of fiberreinforced polymer composites and the fracture mechanics of a variety of reinforced concrete components. He has already issued over 80 research papers with the most prominent journals and conferences in the field of Civil Engineering. 